\title{
STRESS FROM DAILY HASSLES IN COUPLES: ITS EFFECTS ON INTRADYADIC STRESS, RELATIONSHIP SATISFACTION, AND PHYSICAL AND PSYCHOLOGICAL WELL-BEING
}

\author{
Mariana K. Falconier \\ Virginia Polytechnic Institute and State University \\ Fridtjof Nussbeck \\ University of Bielefeld \\ Guy Bodenmann \\ University of Zurich \\ Hulka Schneider and Thomas Bradbury \\ University of California
}

\begin{abstract}
According to the systemic-transactional stress model (STM; G. Bodenmann, European Review of Applied Psychology, 1997; 47: 137), extradyadic stress from daily hassles can have a negative impact on the individual psychological and physical health and the couple's relationship. This study is the first one to test the STM propositions in a model that includes both partners' individual and relational outcomes simultaneously. The model also includes actor and partner effects as well as the interdependence between partners' processes. Cross-sectional, self-report data were collected from 110 community couples in Switzerland. Consistent with STM predictions, results from the path model analysis indicate that for actor effects extradyadic stress from daily hassles relates directly to lower psychological (increase in anxiety symptoms) and physical well-being and only indirectly to lower relationship satisfaction through increased intradyadic stress from relationship problems and also through more depressive symptomatology in men. The female extradyadic stress and intradyadic stress had partner effects on the male intradyadic stress and the male relationship satisfaction, respectively. Limitations as well as research and clinical implications for marriage and family therapists are discussed.
\end{abstract}

Several decades of research have consistently shown that stress poses risk not only for individual functioning but also for couples' relationships. At the individual level, stress has been associated with a wide range of physical problems such as cardiovascular issues, diabetes, and immune dysregulation (for a review see Robles \& Kiecolt-Glaser, 2003) and negative psychological outcomes including mood disorders, sexual problems, and substance abuse (Howe, Levy, \& Caplan, 2004; Koob \& Kreek, 2007; Proulx, Helms, \& Buehler, 2007). At the couple level, various sources of stress have been associated with psychological and physical aggression, communication problems, and relationship dissatisfaction and dissolution (for a review see Allen, Rhoades, Stanley, \& Markman, 2010; Buck \& Neff, 2012; Langer, Lawrence, \& Barry, 2008; Story \& Bradbury, 2004). Understanding the mechanisms through which stress affects partners individually and in their

Mariana K. Falconier, PhD, Department of Human Development, Virginia Polytechnic Institute and State University; Fridtjof Nussbeck, PhD, Department of Psychology, University of Bielefeld; Guy Bodenmann, PhD, Department of Psychology, University of Zurich; Hulka Schneider, PhD and Thomas Bradbury, PhD, Department of Psychology, University of California.

Address correspondence to Mariana K. Falconier, Marriage and Family Therapy Program, Department of Human Development, Virginia Polytechnic Institute and State University, 7054 Haycock Road, Suite 202C, Falls Church, Virginia 22043; E-mail: marianak@vt.edu 
relationship is essential for prevention and intervention efforts. This article reports the results of a study that examined the ways in which stress from daily hassles affects partners' individual psychological and physical well-being and their couples' relationship. The study was guided by author's systemic-transactional model (STM; Bodenmann, 1997), which offers a systems-oriented approach to understand stress processes in the context of couple's relationships. Findings from this study may raise couple therapists' awareness about the potential negative effects of daily hassles stress on individuals and their couples' relationship and the need to help partners develop effective coping strategies.

\section{THE SYSTEMIC-TRANSACTIONAL MODEL}

For several decades, stress processes and coping were examined from models focusing on the individual and that were developed outside the marriage and family therapy (MFT) field. Lazarus and Folkman's (1984) transactional approach, which was the most influential stress theory guiding that research, proposed that individuals experience stress when the perceived demands of a situation exceed the perceived resources to meet those demands. In the 1980s, McCubbin and Patterson (1983) developed the double ABC-X model ( $\mathrm{A}=$ stressor; $\mathrm{B}=$ resources; $\mathrm{C}=$ perception of stressor; X = crisis) based on Rueben Hill's (1949) initial ABC-X model to understand families' responses to major stressful events (e.g., war, crimes, accidents, death). It was not until the 1990s that researchers began to focus specifically on stress processes in the context of couple's relationships.

Research on couples' stress and coping processes has been conducted largely by clinical and social psychologists. Nonetheless, the models developed in this area of research as well as the empirical findings are relevant for the practice of MFT. The most recent review of the literature on stress processes in couples (Randall \& Bodenmann, 2009) identified two models as guiding most studies: the vulnerability-stress-adaptation model (Karney \& Bradbury, 1995) and the STM (Bodenmann, 1997). Karney and Bradbury (1995) developed the vulnerability-stress-adaptation model to explain the effects of external stressors on couples. According to this model, the extent to which stressors external to the couple's relationship affect that relationship depends not only on the nature of the stressful event but also on partners' enduring vulnerabilities (e.g., problematic personality traits) and adaptive processes (e.g., ability to provide support). The STM (Bodenmann, 1997) applied a systemic perspective to Lazarus and Folkman's (1984) transactional stress theory and emphasizes both partners' interdependence and reciprocal influence in the stress and coping processes. In other words, STM considers that one partner's stress appraisal, experience, and coping depend on the other partner's, and therefore, one partner's stress and coping experience cannot be understood without considering the other partner's experience. It is this systemic focus and emphasis on partners' interdependence processes that make STM a useful conceptual model in the MFT field as it is consistent with MFT models' systemic orientation (Nichols \& Schwartz, 2006).

In addition, and unlike the ABC-X model and the vulnerability-stress-adaptation model, STM views the couple's relationship not only as being affected by external stressors but also as a source of stress itself (intradyadic stress; Bodenmann, Ledermann, \& Bradbury, 2007). Couples experience external or extradyadic stress from situations that originate outside the couple such as challenges related to the workplace, finances, children, extended family members, neighbors, friends, community, etc. By contrast, internal or intradyadic stress, also called relationship stress, refers to the stress experienced from situations that arise within the couple's relationship such as incompatibility, conflict, and disagreement between the partners regarding values, goals, attitudes, and habits on various different domains (e.g., childrearing, intimacy, financial management, personal boundaries, recreational time, etc.). According to STM, extradyadic stress increases the partners' likelihood of experiencing individual physical and psychological distress as well as intradyadic stress (spill-over of external stress into the dyad). This means that the couple's dynamics are likely to be affected negatively by the subjective stress that each partner experiences from external stressors, creating in turn an additional source of stress for both partners.

Systemic-transactional model has also proposed that dyadic coping, which refers to the strategies that partners use to cope with stress, either by providing support to each other or relying on conjoint efforts to deal with common stressors, protects couples from the negative effects of stress. 
This aspect of the STM model has received support in studies conducted not only in the U.S. (Papp \& Witt, 2010) but also in France (Untas, Quintard, Koleck, Borteyrou, \& Azencot, 2009), Germany (Herzberg, 2012), and Italy (Iafrate, Bertoni, Margola, Cigoli, \& Acitelli, 2012) among other countries.

Even though the STM model has been applied to the study of couples coping with major external stressors such as breast cancer (Badr, Carmack, Kashy, Cristofanilli, \& Revenson, 2010) or life-threatening cancer not responding to first-line therapies (Fife Betsy, Weaver Michael, Cook William, \& Stump Timothy, 2013), STM considers chronic minor external stressors or daily hassles to be a source of significant extradyadic stress for couples (Revenson \& Lepore, 2012). Daily hassles may range from losing a cellular phone to dealing with a difficult coworker or handling competing work and home demands. Unlike some major and/or acute stressors such as unemployment or a terminal illness that may either lead a couple to separate or provide an opportunity for mutual support and growth (Williams, 1995), the pile-up of daily hassles has been found to be associated consistently with poor relationship quality and divorce (Totenhagen, Butler, \& Ridley, 2012).

\section{Daily Hassles and Relationship Functioning: Pathways of Influence}

In explaining the effect of daily hassles on couple's functioning, STM argues that partners' extradyadic stress from daily hassles may not only reduce relationship satisfaction in a direct way but also indirectly through two main mediating mechanisms: increase in intradyadic stress (relationship stress) and deterioration of individual psychological and physical well-being (Figure 1). Partners stressed from daily hassles may tend to spend less time together as a couple, reducing their sense of togetherness and intimacy. Problematic personal characteristics such as hostility, intolerance, or rigidity may be exacerbated and manifest more prominently, which may contribute to negative interactions. In addition, due to their seemingly triviality, daily hassles may not be accompanied by a partner's support or empathic understanding as major life stressors often are. This emotional distance and conflict that daily hassles may bring to the relationship can create additional sources of stress for each partner, which in turn may contribute to feeling less satisfied with the couple's relationship. Two studies have already provided empirical support for the mediating role of intradyadic stress in the association between extradyadic stress from daily hassles and reduced relationship satisfaction (Bodenmann, Ledermann, \& Bradbury, 2007; Ledermann, Bodenmann, Rudaz, \& Bradbury, 2010).

Regarding the second mediating mechanism, STM argues that the ongoing presence of minor stress creates psychological distress (e.g., increase in depressive and anxiety symptoms) and reduces physical well-being (e.g., headaches or back pain), which in turn affects partners' levels of satisfaction with their couple's relationship (Randall \& Bodenmann, 2009). Despite its rational appeal, no study has examined the mediating role of deterioration of physical and psychological health in the link between daily hassles stress and reduced relationship satisfaction. Most studies have either focused on the impact of stress on individual well-being (Serido, Almeida, \& Wethington, 2004) or on couple's functioning (Neff \& Karney, 2009) separately but not on both simultaneously. Nonetheless, findings linking poor physical health, anxiety, and/or depression with stress on the one hand and lower relationship satisfaction on the other suggest that deterioration of physical and psychological well-being might be playing such a mediating role. Stressful life events (for a review see Liu \& Alloy, 2010), general chronic stress (Mckintosh, Gillanders, \& Rodgers, 2010; Stefanek, Dagmar, Hildegunn, \& Spiel, 2012), and work stress (Rusli, Edimansyah, \& Naing, 2008) have all been found to be associated with symptoms of depression and/or anxiety. Various studies have also reported that an individual's level of depression and/or anxiety can affect their satisfaction with their couple's relationship (Atkins, Bortnik, Hahlweg, \& Klann, 2011; Lemmens, Buysee, Heene, Eisler, \& Demyttenaere, 2007; Whisman \& Uebelacker, 2009). Poor physical health has also been associated with increased stress (for a review see Robles \& Kiecolt-Glaser, 2003) and relationship difficulties (Hawkins \& Booth, 2005; Umberson, Williams, Powers, Liu, \& Needham, 2006).

\section{PURPOSE OF THE PRESENT STUDY}

The main goal of this study is to test STM proposed mechanisms of influence by including not only both partners' experiences of extra- and intradyadic stress and relationship satisfaction but 


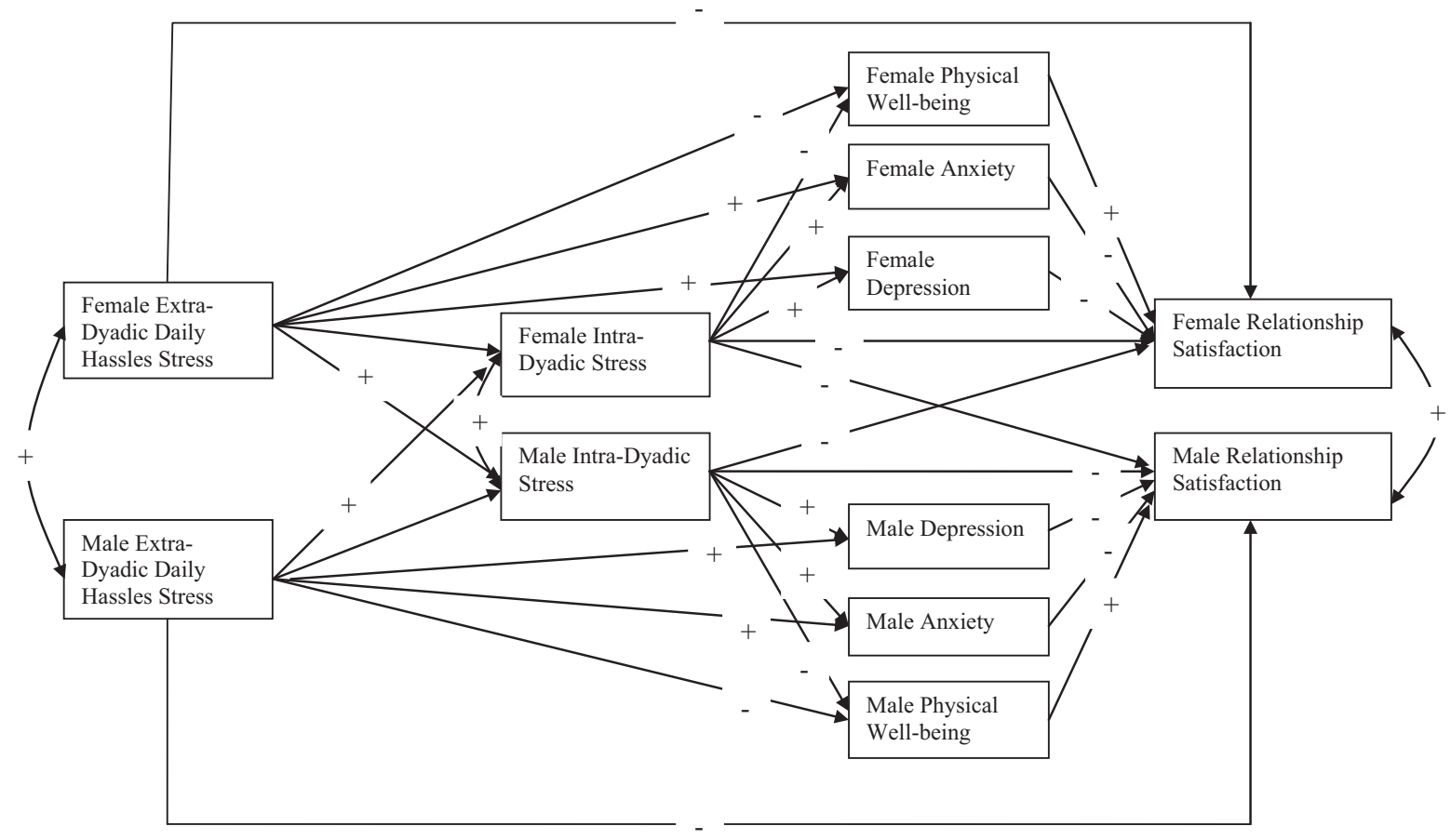

Figure 1. Conceptual Model.

Note. The model also includes covariances between partners' physical well-being, anxiety and depression (not depicted for clarity of presentation). Covariances are between error terms. Length of relationship was controlled for by adding it as an exogenous variable affecting all variables. Positive statistical associations are depicted with " + ", negative associations with "-".

also their individual physical well-being as well as their depression and anxiety symptoms. Examining both individual and relational outcomes within the same model allows for a more complete understanding of the individual and relational effects of stress in couples as each effect is controlled for the other postulated effects. In addition, by examining both partners' variables within the same stress model, this study allows for the examination and control of both actor and partner effects, which is consistent with the actor-partner interdependence model (APIM; Kenny, Kashy, \& Cook, 2006) approach to treat partners' interdependence.

Even though STM is a not a treatment model like most MFT models are, it may be useful to couples' therapists as it offers a conceptual model that can guide the assessment of couples' interactions and areas of intervention by explaining how daily hassles stress can create relationship tensions as well as deteriorate each partner's individual physical and psychological well-being.

\section{Hypotheses}

The main goal of the present study is to test the propositions advanced by STM using an APIM approach with data collected from both partners. Below is a list of the hypotheses that are part of the conceptual model depicted in Figure 1.

1. Each partner's extradyadic stress from daily hassles will have a direct negative association with their own relationship satisfaction.

2. Each partner's extradyadic stress from daily hassles will also have an indirect negative association with their own relationship satisfaction through the mediating mechanisms listed below and with their partner's relationship satisfaction through mediating mechanism a.

a. Increases in the each partner's intradyadic stress (stress from problems internal to the couple's relationship).

b. Increases in their own symptoms of depression and anxiety.

c. Decreases in their own physical well-being. 
Given that marital negative interactions have been found to be associated with symptoms of depression (Whisman \& Uebelacker, 2009) and anxiety (Addis \& Bernard, 2002; Chambless, Bryan, Aiken, Steketee, \& Hooley, 2001) and poor health outcomes (Hawkins \& Booth, 2005; Umberson et al., 2006), it is expected that partner's intradyadic stress may also affect their own physical health and symptoms of depression and anxiety. Therefore, a third hypothesis is included.

3. Each partner's intradyadic stress will have not only a direct but also an indirect association with their own relationship satisfaction through the following mechanisms:

(a). Increases in their own symptoms of depression and anxiety.

(b). Decreases in their own physical well-being.

To control for partners' interdependence and in line with the assumptions of APIM, the model includes associations between all (residual) variables at the same stage of the presumed path model, that is, the external variables of external stress are correlated; both variables depicting the internal stress are correlated (residual correlation); female and male well-being, anxiety, and depression are intercorrelated (residual correlations) as are the two relationship satisfaction variables (residual correlations). These residual correlations need to be included since both partners' scores may be associated to a higher degree than expected by the predictors (above and beyond their effects; Kenny et al., 2006). The model also includes associations between the error terms of physical well-being and symptoms of anxiety and depression for each partner as past research has provided evidence of such associations (Ormel, Rijsdijk, Sullivan, van Sonderen, \& Kempen, 2002). Controlling for these relationships prevents finding spurious relationships.

\section{METHOD}

\section{Participants}

Participants were 110 heterosexual couples from a community sample residing in the German speaking part of Switzerland. To participate in the study, both partners had to be at least 18 years old and in their current committed relationship for at least 1 year. On average, men were 44.4 years old $(S D=15.93)$ and women were 41.22 years old $(S D=15.56)$. In terms of educational level, $47.2 \%$ of men and $72.7 \%$ of women held a high school degree, whereas $51.8 \%$ of men and $26.4 \%$ of women held at least an undergraduate degree. Most men $(88.1 \%)$ were either working or studying, whereas for women $45.5 \%$ were employed, $28.2 \%$ were homemakers, and $21.8 \%$ were students. Individual income ranged from 20,000 to 80,000 USD, which at the time of data collection meant that couples were middle-class in Switzerland (Federal Statistical Office, 2013). The majority of men (58.2\%) and women (50.9\%) were Protestant, $17.3 \%$ of men and $25.5 \%$ of women were Catholic, $15.5 \%$ of men and $13.6 \%$ of women had other religious affiliation, and $9.1 \%$ of men and $10 \%$ of women reported no religious affiliation at all. Even though all couples had been together in a committed relationship for a least a year, only $75.5 \%$ of them were living together and $54.5 \%$ had children. The average length of the relationship was 18.21 years $(S D=13.78)$. Results from ANOVAs did not indicate any significant difference between cohabitating couples and those that were not on any of the variables of interest in this study.

\section{Procedure}

Community couples were recruited through newspaper ads and flyers posted in medical offices in order to get a broader range in physical health, as studies based on community samples usually fail to have enough variance in this variable due to a relatively good physical health in Switzerland (Swiss Health Observatory, 2008). Every couple interested in participating was either handed or mailed two sets of questionnaires, one for each partner. Each set included a consent letter, instructions and questionnaires that should be completed independently without consulting the partner and returned within 2 weeks. Questionnaires did not include any identifying information except for an impersonal code linking the two partners' questionnaires. Participants were not reimbursed. Out of the 650 questionnaires that were distributed, 265 were returned but 45 were excluded from statistical analyses as only one partner had fully completed the questionnaires. 


\section{Measures}

All measures were completed in German. On the demographic form, participants provided information on age, gender, country of origin, educational and income level, employment status, relationship status, relationship duration, number of children, and religious affiliation.

Extradyadic Stress from daily hassles. The 8-item chronic extradyadic stress subscale from the 30-item Multidimensional Stress Questionnaire for Couples [MSQ-C; Bodenmann, 2006) that was used in past studies (Bodenmann, Ledermann, \& Bradbury, 2007) to assess extradyadic stress from daily hassles was also used in the present study. The MSQ-C is an adaptation of the original Hassles Scale (Kanner, Coyne, Schaefer, \& Lazarus, 1981) that included minor stressors, both internal and external to the relationship (for a description of this adaptation, Bodenmann, 2006). Respondents rate how stressful daily situations outside their couple's relationship (e.g., work load, financial problems, conflict with colleagues or friends, etc.) have been over the past 12 months on a 4-point Likert-type scale ranging from $1=$ not at all to $4=$ highly stressful. As the measure covers different life domains, it cannot be considered a psychometric scale, yet the mean score of all eight items reflects the individual stress level.

Intradyadic Stress. Similar to previous studies (Bodenmann, Ledermann, \& Bradbury, 2007), the 10-item chronic intradyadic stress subscale from the MSQ-C was used to assess chronic stress internal to the couple's relationship. Respondents rate on a 4-point Likert-type scale (ranging from $1=$ not at all to $4=$ highly stressful) how stressful situations originating within the couple's relationship (e.g., arguments, differences in attitudes, disturbing habits of the partner, feeling neglected by the partner) have been over the past 12 months. The validity and reliability of the MSQ-C have been established in previous studies in German (Bodenmann, 2006). In the present study, the internal consistency of this scale was $\alpha=.82$ for men and $\alpha=.84$ for women.

Symptoms of depression and anxiety. Each type of symptoms was assessed with the 7-item anxiety subscale and the 7-item depression subscale from the German version of the Depression Anxiety and Stress Scales-21 (DASS-21; Lovibond \& Lovibond, 1995), available from the DASS website (http://www2.psy.unsw.edu.au/groups/dass). Each of these subscales asks respondents to rate the frequency with which they have experienced symptoms of either depression (e.g., lack of enthusiasm, low self-worth, sadness, etc.) or anxiety (e.g., physiological agitation, breathing difficulties, etc.) within the past week on a 5-point Likert-type scale ranging from $0=$ never to 3 = everyday. Even though the German version of the DASS has not been validated, the English version of the DASS has been validated in various previous studies (Crawford \& Henry, 2003; Henry \& Crawford, 2005). The internal consistency was $\alpha=.77$ for men and $\alpha=.87$ for women (depression subscale) and $\alpha=.64$ for men and $\alpha=.62$ for women (anxiety subscale).

Physical Well-being. The Physical Well-being Questionnaire (PWBQ; Mohr, 1986) assesses 18 different physical symptoms (e.g., back pain, headaches) in the last 2 weeks on a 5-point Likerttype scale ranging from $0=$ never to $4=$ every day. The reliability and validity of the PWBQ have been established for the PWBQ in German (Mohr, 1986).In the present study, the internal consistency was $\alpha=.89$ for men and $\alpha=.90$ for women.

Relationship satisfaction. The German validated version by Sander and Böcker (1993) of the 7-item Relationship Assessment Scale (RAS; Hendrick, 1988) was used to assess relationship satisfaction. The RAS measures global relationship satisfaction on a 5-point Likert-type scale ranging from $1=$ low to $5=$ high. The validity and reliability of the RAS are well established (Hendrick, Dicke, \& Hendrick, 1998). In this study, the internal consistency was $\alpha=.88$ for men and $\alpha=.92$ for women.

\section{Analytic Strategy}

Given that the data were not normally distributed at the multivariate level (Yuan, Lambert, and Fouladi's (2004) normalized coefficient $=9.163$ ), Spearman's correlations were used to examine the intercorrelational matrix among variables and the Wilcoxon signed rank test for paired samples was used to analyze gender differences in variables. Path model analysis using EQS 6.1. and the maximum likelihood estimation method were used to test the conceptual model. Model fit was assessed through the robust Yuan-Bentler scaled chi-square $\left(\chi_{\mathrm{YB}}^{2}\right)$, an adjusted chi-square statistic used with non-normal data (Yuan \& Bentler, 2000). Model fit was also evaluated with the three fit indices recommended by Hu and Bentler (1999): robust Bentler's Comparative Fit Index 
(CFI $>.96)$, the standardized root mean square residual (SRMR $<.08$ ), and the robust root mean square residual of approximation (RMSEA < .06). As an additional indicator of model fit, the langrage multiplier (LM) coefficients were inspected to search for possible model misspecifications. Due to the sample size of 110 couples, only length of relationship was controlled by adding it as an exogenous variable affecting all variables. This demographic variable tends to correlate highly with other demographic variables such as presence of children and age, which was also true in this study (presence of children $r=.75$; men's age $r=.90$; women's age $r=.93$ ). To test the significance of mediation effects for non-normal distributions, EQS provides a corrected statistic for the Sobel test of indirect effects.

\section{RESULTS}

Results from the Wilcoxon signed rank test (Table 1) indicated that women experienced significantly more extradyadic stress from daily hassles (women $M=1.74, S D=0.43$; men $M=1.61, S D=0.33$ ), intradyadic stress (women $M=1.66, S D=0.46 ;$ men $M=1.58$, $S D=0.41$ ), symptoms of depression (women $M=5.62, S D=6.43$; men $M=4.02, S D=4.32$ ), and symptoms of anxiety (women $M=2.99, S D=3.72$; men $M=2.04, S D=6.43$ ), as well as significantly lower levels of physical well-being (women $M=3.83, S D=0.56$; men $M=4.13$, $S D=0.55)$ than men. No significant differences were found between partners' relationship satisfaction (women $M=4.33, S D=0.63$; men $M=4.42, S D=0.54$ ).

Table 2 reports the coefficients for the Spearman's bivariate correlations among path model variables. Except for the coefficient between the female extradyadic stress from daily hassles and her intradyadic stress $(r=.68)$, significant correlation coefficients ranged from $r=0.23$ to $r=0.52$. Significant correlations between scores of partners on the same variable confirmed the need to control for partners' interdependence in the main model using APIM.

Results from path model analysis showed an acceptable fit to the data $\left(\chi_{\mathrm{AB}}^{2}(26)=36.23\right.$, $p=.09$; robust CFI $=.973$; SRMR $=.054$; RMSEA $=.055(.000, .099)$. A conceptual examination of the LM test results did not suggest any misspecification of the model. Standardized results with both statistically $(p<.05)$ and nonstatistically significant paths are presented in Figure 2.

Contrary to Hypothesis 1, no direct association was found between each partner's extradyadic stress from daily hassles and their own relationship satisfaction (men $\beta=.12$; women $\beta=.00$ ). Nonetheless, in support of Hypothesis 2, an indirect, negative association between each partner's daily hassles stress and their own relationship satisfaction (men: $\beta_{\text {indirect }}=-.19$; women: $\left.\beta_{\text {indirect }}=-.40\right)$ was found. Sobel tests indicated those indirect effects were significant for men $(t=-2.13, p<.05)$ and for women $(t=-3.78, p<.05)$. Regarding the hypothesized mediating

Table 1

Descriptive Statistics and Probability for the Wilcoxon Signed Rank Test for Paired Samples

\begin{tabular}{|c|c|c|c|c|c|c|}
\hline & \multicolumn{2}{|l|}{ Men } & \multicolumn{2}{|c|}{ Women } & \multirow[b]{2}{*}{$Z$} & \multirow{2}{*}{$\begin{array}{l}\text { Wilcoxon Signed } \\
\text { Rank Test Probability }\end{array}$} \\
\hline & $M$ & $S D$ & $M$ & $S D$ & & \\
\hline Extradyadic daily hassles stress & 1.61 & 0.33 & 1.74 & 0.43 & -2.31 & .02 \\
\hline Intradyadic stress & 1.58 & 0.41 & 1.66 & 0.46 & -2.10 & .04 \\
\hline Depressive symptoms & 4.02 & 4.32 & 5.62 & 6.43 & -2.28 & .02 \\
\hline Anxiety symptoms & 2.04 & 6.43 & 2.99 & 3.72 & -2.39 & .02 \\
\hline Physical well-being & 4.13 & 0.55 & 3.83 & 0.56 & -4.21 & .00 \\
\hline Relationship satisfaction & 4.42 & 0.54 & 4.33 & 0.63 & -1.42 & .16 \\
\hline
\end{tabular}


Table 2

Intercorrelations Among Path Model Variable for Women (Above Diagonal) and Men (Below Diagonal) and Dyads (Bolded Diagonal)

\begin{tabular}{|llllllll|}
\hline Variables & 1 & 2 & 3 & 4 & 5 & 6 \\
\hline 1. Extradyadic daily hassles stress & $\mathbf{. 1 6}$ & $.44^{* *}$ & .17 & $.27^{* *}$ & $-.39^{* *}$ & $-.33^{* *}$ \\
2. Intradyadic Stress & $.32^{* *}$ & $.7^{* *}$ & $.37^{* *}$ & .06 & $-.27^{* *}$ & $-.68^{* *}$ \\
3. Symptoms of depression & $.34^{*}$ & $.35^{* *}$ &. $\mathbf{2 0 *}$ & $.29^{* *}$ & $-.31^{* *}$ & $-.37^{* *}$ \\
4. Symptoms of anxiety & $.42^{* *}$ & $.34^{* *}$ & $.51^{* *}$ &. $\mathbf{0 7}$ & $-.52^{* *}$ & -.09 \\
5. Physical well-being & $-.42^{* *}$ & $-.23^{*}$ & $-.42^{* *}$ & $-.51^{* *}$ & $\mathbf{. 1 6}$ & $.29^{* *}$ \\
6. Relationship satisfaction & -.01 & $-.55^{* *}$ & $-.30^{* *}$ & -.16 & .11 & $\mathbf{. 5 0 * *}$ \\
\hline
\end{tabular}

Note. $N=110$ men and 110 women. Correlations between the dyad members are presented in bold along the diagonal. ${ }^{*} p<.05 ; * *<.01$ (one-tailed).

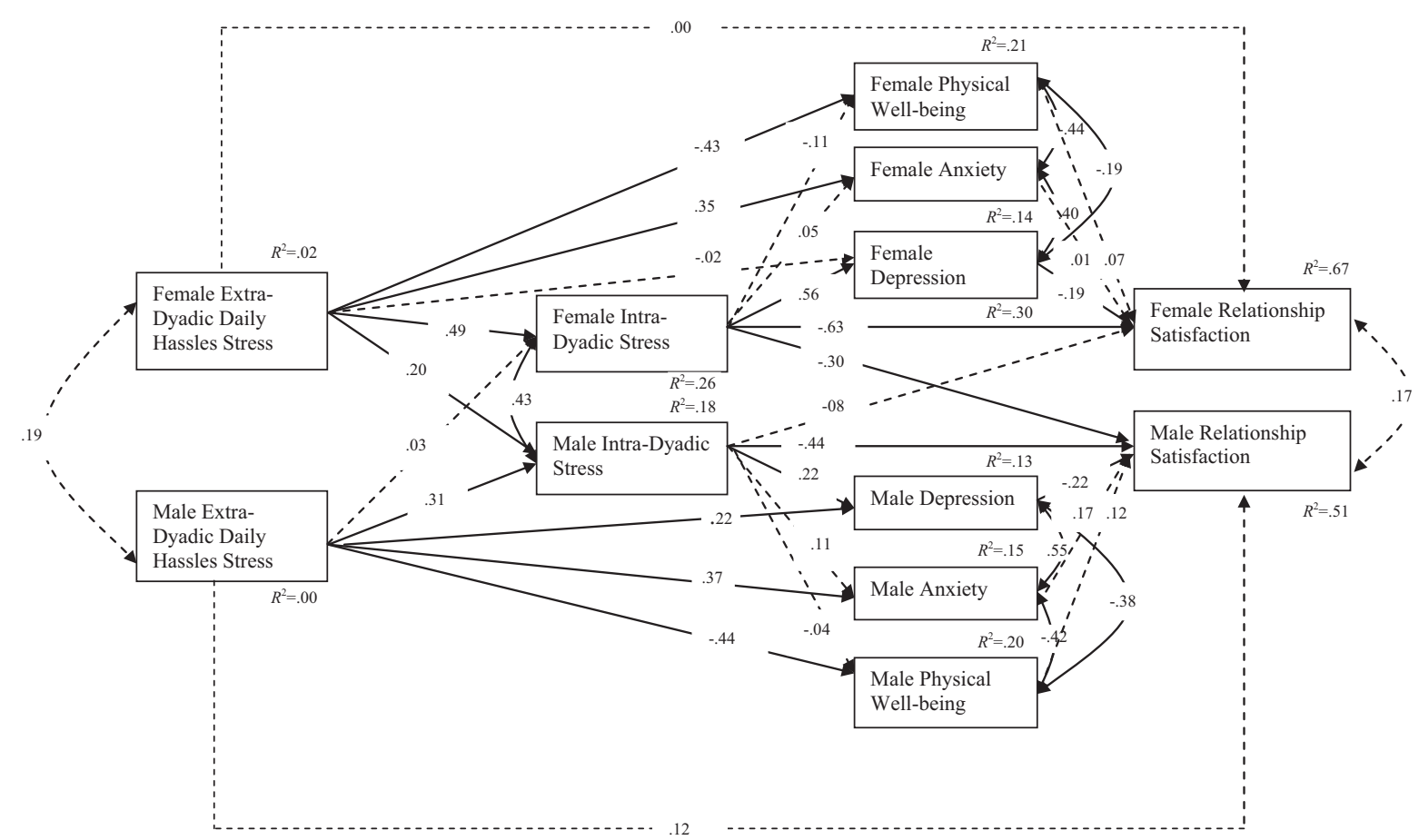

Figure 2. Standardized results with statistically significant paths. $\left(\chi_{\mathrm{AB}}^{2}(26)=36.23, p=.09\right.$; robust CFI $=.973 ; \mathrm{SRMR}=.054 ; \mathrm{RMSEA}=.055(.000, .099)$. Only significant paths at the .05 level have been included).

Note. Full lines depict significant paths $(p<.05)$ and broken lines depict nonsignificant paths. The model also includes covariances between partners' physical well-being, anxiety, and depression. Covariances are between error terms. Length of relationship was controlled for by adding it as an exogenous variable affecting all variables.

mechanisms, intradyadic stress seemed to play a mediating role. Each partner's extradyadic stress from daily hassles was positively associated with their own intradyadic stress from relationship problems (men $\beta=.31$; women $\beta=.49$ ), which in turn was negatively associated with their own relationship satisfaction directly (men $\beta=-.44$; women $\beta=-.63$ ) and indirectly through their own symptoms of depression. Sobel tests indicated that each partners' intradyadic stress had an indirect, negative effect (men: $\beta_{\text {indirect }}=-.12$; women: $\beta_{\text {indirect }}=-.12$ ) on their own relationship 
satisfaction (men: $t=-2.06, p<.05$; women: $t=-2.02, p<.05$ ). Each partner's intradyadic stress was positively related to their own symptoms of depression (men $\beta=.22$; women $\beta=56$ ), which were in turn negatively associated with their own relationship satisfaction (men $\beta=-.22$; women $\beta=-.19$ ).

Contrary to expectations, neither symptoms of anxiety nor physical well-being mediated the negative association between extradyadic stress from daily hassles and relationship satisfaction. Even though each partner's stress from daily hassles was statistically significantly associated with both symptoms of anxiety (men $\beta=.37$; women $\beta=.35$ ) and physical well-being (men $\beta=-.44$; women $\beta=-.43$ ), relationship satisfaction was not for either symptoms of anxiety (men $\beta=.17$; women $\beta=.01$ ) or physical well-being (men $\beta=.12$; women $\beta=.07$ ). There was also a trend of an association of the male symptoms of anxiety and physical well-being with his relationship satisfaction. Unlike physical well-being and symptoms of anxiety, symptoms of depression mediated the link between extradyadic stress from daily hassles and relationship satisfaction but only for men. Male stress from daily hassles was positively related to his own symptoms of depression $(\beta=.22)$, which were in turn associated negatively with the male relationship satisfaction $(\beta=-.22)$. By contrast, the female daily hassles stress was not associated with her own symptoms of depression $(\beta=-.02)$.

There was also a partner effect of the female extradyadic stress from daily hassles as it was indirectly associated with the male relationship satisfaction $\left(\beta_{\text {indirect }}=-.24\right)$ through both partners' intradyadic stress. The Sobel test indicated that this negative indirect effect was statistically significant $(t=-4.02 ; p<.05)$. The female stress from daily hassles had not only a significant, positive actor effect $(\beta=.49)$ but also a significant positive, partner effect $(\beta=.20)$. In turn, the male intradyadic stress was negatively associated with his own relationship satisfaction $(\beta=-.44)$ and the female intradyadic stress had a partner effect on relationship satisfaction $(\beta=-.30)$. Except for the partner effects of the female intra- and extradyadic stress, no other partner effects were statistically significant in the model.

The path model analysis also indicated significant positive residual correlations between both partners' level of intradyadic stress $(=.43)$ and physical well-being $(=.17)$. Both partners' intradyadic stress was associated above and beyond the association that can be explained by both partners' extradyadic stress from daily hassles. No significant residual correlations were found between both partners' daily hassles stress $(=.19)$, symptoms of depression $(=.11)$ and anxiety $(=.10)$, and relationship satisfaction $(=.17)$. Residuals for anxiety and depression symptoms were positively correlated for both men $(=.55)$ and women $(=.40)$ and so was physical well-being with symptoms of anxiety ( $\mathrm{men}=-.42$; women $=-.44$ ). Symptoms of anxiety correlated positively with physical well-being (men $=-.38$; women $=-.19$ ). The full model accounted for $67 \%$ and $51 \%$ of the variation in female and male relationship satisfaction, respectively.

\section{DISCUSSION}

The main goal of the present study was to test and provide support for the propositions advanced by the STM that emphasizes that partners' stress processes are interdependent and explains the mechanisms through which extradyadic stress from daily hassles can have individual and relational effects in couples. STM argues that it is not just major stressful events external to the couple that can have negative effects on individuals and relationships but that it is also the extradyadic stress from daily hassles, whose potential harmful effects are often underestimated, that can also contribute directly and indirectly to deteriorate each partner's individual physical and psychological health and the couple's relationship. Unlike previous studies, the model tested in this study included both individual and relational outcomes as well as indicators of both, psychological and physical functioning. Results from the test of this model are consistent with many of STM predictions and can inform assessment and treatment in couples' therapy.

Findings have to be considered in light of the fact that women in this study reported to experience more stress and poorer psychological and physical well-being than their partners, which is in line with gender differences found in past studies (Bouchard \& Shih, 2013; Kiecolt-Glasser \& Newton, 2001; Neff \& Karney, 2005; Zwicker \& DeLongis, 2010). Compared to their male partners, women reported higher levels of extradyadic stress from daily hassles and intradyadic stress 
from relationship problems as well more symptoms of depression and anxiety. Nonetheless, women still reported to be as equally satisfied with their couple's relationship as their partners did.

According to STM, the external stress from daily hassles decrease partners' satisfaction with their relationship not only directly but also indirectly by having negative effects on the individual psychological and physical health as well as by increasing the intradyadic stress from relationship problems. When all factors involving individual and relational outcomes were considered, there was no evidence of a direct association between daily hassles stress and relationship satisfaction. The absence of such a direct link differs from Ledermann, Bodenmann, Rudaz, and Bradbury (2010) finding in their study, which may be suggesting that any seemingly direct association between stress from daily hassles and relationship satisfaction may not be significant once more mediating mechanisms such as changes in psychological well-being (which was not part of Ledermann, Bodenmann, Rudaz, \& Bradbury model) are included.

Nonetheless, our results did support STM's proposition of an indirect association between extradyadic stress from daily hassles and relationship satisfaction for both partners with intradyadic stress mediating the association. In other words, for both partners, the stress that each of them experienced from daily hassles was related to experiencing more intradyadic stress, which in turn was associated with lower relationship satisfaction. Additionally, each partner's intradyadic stress had not only direct but also indirect effects on their own relationship satisfaction through increases in their symptoms of depression. For men, increased symptoms of depression also mediated the daily hassles stress - relationship satisfaction negative association. In addition to these actor effects, partner effects were found for both extra- and intradyadic stress for women. Their daily hassles stress was related directly with increases in the male intradyadic stress and indirectly with decreases in the male relationship satisfaction (through both partners' intradyadic stress), whereas the female intradyadic stress was positively related to the male relationship satisfaction.

This set of findings suggests that stress from daily hassles does have an effect on intradyadic stress and on relationship satisfaction. Nonetheless, the gender differences found in partner effects may be suggesting that women's stress from both sources, external and internal to the relationship pose more risks for the couple's sense of satisfaction with their relationship. One possible explanation for this gender difference is that women tend to communicate about their stress to their partners more openly and explicitly than men do (Neff \& Karney, 2005), and therefore, their stress levels may increase the stress stemming from the couple's problems not only for them but also for their male partners (Taylor, 2011; Taylor et al., 2000). Similarly, women may communicate their stress from relationship problems more frequently and openly than men do, which may contribute to more relationship dissatisfaction in men as well. Another possibility is that men may respond more negatively and less supportively to their partner's stress than women do, which may contribute to conflict in the relationship. A study by Neff and Karney (2005) using observational and diary data from 169 couples revealed that on more stressful days women tended to provide more support, whereas men, even though they provided support, also increased the negative behaviors toward their partners such as criticizing, blaming the partner or providing inconsiderate advice. Men's negative behaviors in response to their partner's stress may increase conflict and lead to intradyadic stress and relationship dissatisfaction.

Interestingly, for both men and women, their external stress from daily hassles was related directly to increased anxiety and deterioration of physical well-being but neither of these two changes at the individual level related to changes in either intradyadic stress or relationship satisfaction. When all results are considered together, it seems that, in terms of direct effects, for both partners extradyadic stress is associated with anxiety and physical well-being, whereas intradyadic stress with depression and relationship satisfaction. These results might be suggesting different individual and relational effects of stress depending on whether the stress originates within or outside the dyad. Even though further studies should examine this possibility, in the meantime our results indicate that it might be important to discriminate between intra- and extradyadic stress and between depressive and anxiety symptoms when studying stress processes in couples.

In sum, results in the present study replicated the finding from two previous studies that extradyadic stress from daily hassles has an indirect actor effect on relationship satisfaction through increased intradyadic stress. Unlike previous studies, it was found that (a) the female extra- and intradyadic stress has a negative partner effect on relationship satisfaction, (b) the mediating role of 
intradyadic stress was present above and beyond the negative effects of daily hassles stress on psychological and physical well-being and (c) symptoms of depression mediated the negative association between daily hassles stress and relationship satisfaction for men as well as the association between intradyadic stress and relationship satisfaction for both partners.

\section{Limitations}

Despite the direction of relationships proposed by STM, the cross-sectional nature of the data used in this study prevents us from drawing any definite conclusions about causal direction. Our results can only be viewed as consistent and therefore, supportive, of the STM propositions but they cannot rule out the possibility that other models may also fit the data acceptably.

This study has also relied on self-report instruments, which may have introduced a social desirability bias in the data. Besides, reliance on self-report measures may have inflated relations among stress, individual physical and psychological well-being, and relationship satisfaction. It is also important to caution about the generalizability of the present findings as they may be related to the use of a convenience sample and the relatively high level of individual psychological and physical health and relationship satisfaction of the couples that participated in this study.

\section{Implications for the STM Model}

There are some important implications for STM that can be derived from the present study's findings. First, STM is not specific regarding potential gender differences and similar effects of stress on couple's functioning are assumed. Our findings suggest that a more gender-specific formulation is necessary in a revision of STM. Second, STM proposes that effects of extradyadic stress on relationship satisfaction are mediated by deterioration in psychological functioning without formulating any specific manifestation of psychological problems (e.g., depression or anxiety symptoms). Nonetheless, our findings suggest that the model could be advanced by incorporating more specific formulations about the facets of psychological well-being that may be involved in the ways that stress affects individuals and their romantic relationships. Third, even though physical well-being was not found to mediate the daily hassles stress-relationship satisfaction link in this study, its potential mediating role should be reexamined in future studies. It is possible that more severe physical symptoms related to serious medical conditions or physical problems might play such a role. Unlike the minor physical symptoms (e.g., headaches, backaches) measured in this study, more critical physical conditions can affect sensitive domains of the couple such as sexuality, mobility, etc., and therefore, they may affect partners' relationship satisfaction (Bouras, Vanger, \& Bridges, 1986).

\section{Implications for Marriage and Family Therapists}

Findings from the present study also advance our understanding about stress processes in the context of couples' relationships by providing more information about the way in which stress from daily hassles may affect partners individually and in their relationships. If stress from daily hassles is likely to directly increase anxiety, deteriorate physical health and, raise intradyadic stress (e.g., arguments) but indirectly decrease partners' relationship satisfaction; then, couples' therapists should routinely assess not only for the presence of major external stressors but also for partners' stress levels associated with daily hassles, their effect on individual and relationship functioning, and partners' individual and dyadic coping skills to handle such stress. Even though couple therapists in general will gather information about the couple's context and will ask about coping strategies in the presence of major external stressors (e.g., death, moving, medical diagnosis), very rarely do they assess the impact of daily hassles on partners' individual emotional and physical health and their relationship. Nonetheless, our findings indicate that assessing for the presence of daily hassles and their individual and relational effects is necessary and that those effects should never be underestimated. Furthermore, the STM model and the findings from the present study are reminders for clinicians of the interdependence between partners' stress processes. The present study also suggests that special attention should be given to partner effects when it is the woman that reports experiencing either stress from daily hassles or intradyadic stress as it has effects not only on her relationship satisfaction but also on her partner's. 
The assessment for the presence and effects of extradyadic stress from daily hassles and intradyadic stress can be conducted by asking partners directly about their level of stress and its effects on themselves, their partners, and their couple's relationship or by having partners complete self-report instruments such as the one used in this study. Given that our findings suggest that anxiety symptoms are not associated with intradyadic stress but with stress from daily hassles and depression symptoms are, the presence of anxiety and/or depression symptoms in either partner might guide the clinician's assessment. This assessment can easily be incorporated at the beginning of any MFT treatment model and will enhance the clinician's understanding of the couple's context of interaction and of contributing factors to symptoms of anxiety and lower physical well-being. Moreover, reducing daily hassles or coping with them effectively so that they do not spill into the couple's relationship or deteriorate partners' individual well-being may become the goal of therapy.

In cases where reducing daily hassles and/or improving individual and dyadic coping skills to deal with such hassles become the goals of treatment, interventions to reach those goals will be shaped largely by the MFT model used by the couple therapist. Addressing the way in which each of the available MFT models may conceptualize and address stress and coping processes is beyond the scope of this article. Nonetheless, as an illustration, in cognitive behavioral couples' therapy (CBCT; Epstein \& Baucom, 2002), communication skills training can be used to improve partners' ability to communicate about their daily hassles stress to each other and enhance understanding of each other's stress experience. In CBCT, the therapist may discuss with each partner effective and ineffective ways of handling stress from daily hassles individually and the impact of those strategies on the other partner and their relationship. In addition, CBCT can help partners improve their dyadic coping skills by focusing on the ways that each partner provides practical (e.g., suggesting solutions) and/or emotional (e.g., empathic understanding) support to help the other partner cope and the conjoint coping strategies (e.g., relaxing together, discussing solutions for reducing daily hassles) that the couple relies on to face stress from daily hassles together.

Considering the associations of daily hassles stress with individual and relational functioning, couple therapy interventions aimed at improving coping with daily hassles stress may have a beneficial effect not only on partners' relationship but also on their individual psychological health. In fact, a recent review of research on the treatment of couple distress published in the Journal of Marital and Family Therapy (Lebow, Chambers, Christensen, \& Johnson, 2012) included a recent randomized clinical trial (Bodenmann et al., 2008) that had found that coping-oriented couple therapy, a CBCT-based approach with special emphasis on coping skills, was as effective as interpersonal psychotherapy and individual cognitive behavioral therapy in reducing symptoms of depression and increasing relationship satisfaction and had the lowest relapse rates of depression compared to the other two treatments.

In addition to informing therapy, our findings may contribute to the development of preventive and intervention efforts at a programmatic level. Programs should be directed at sensitizing couples to the harmful effects of extradyadic stress from daily hassles on the individual and the couple's relationship. A thorough description of preventive and intervention efforts to improve individual and dyadic coping strategies is beyond the scope of the present article, but examples of such interventions can be found in the couples coping enhancement training (CCET; Bodenmann $\&$ Shantinath, 2004) designed to help couples cope with stress.

\section{Implications for Research}

Future studies should test the full STM model with longitudinal data to provide support for the direction of causal relationships proposed by STM. These studies should continue collecting data from both partners and apply an APIM approach so that actor and partner effects can be analyzed and controlled for and gender differences can be examined. Future studies should also differentiate between extra- and intradyadic stress as they may have different effects on the individual and the couple's relationship. To strengthen the external validity of the results from the present study and of the STM, future studies should be conducted not only with community but also clinical samples and should include other ethnic populations. Ideally, future studies should seek to assess individual and relational outcomes through brief self-report questionnaires and through physiological, observational, and diary measures. 


\section{CONCLUSION}

Findings from the present study contribute to our understanding about stress processes in the context of couples' relationships by identifying some of the mediating mechanisms through which stress may affect partners individually and in their relationship. Our findings lend further support to the STM model and highlight the importance of examining the effects of daily hassles stress not only on each partner's individual psychological and physical well-being but also on their relationship as this source of extradyadic stress has the potential of increasing intradyadic stress and eventually relationship dissatisfaction. Our results can guide future research and clinical work.

\section{REFERENCES}

Addis, J., \& Bernard, M. E. (2002). Marital adjustment and irrational beliefs. Journal of Rational Emotive Cognitive Behavior Therapy, 20, 3-13.

Allen, E. S., Rhoades, G. K., Stanley, S. M., \& Markman, H. (2010). Hitting home: Relationships between recent deployment, posttraumatic stress symptoms, and marital functioning for army couples. Journal of Family Psychology, 24, 280-288. doi:10.1037/a0019405.

Atkins, D. C., Bortnik, K. E., Hahlweg, K., \& Klann, N. (2011). The association between marital discord and depression in a community-based sample of couples seeking treatment. Journal of Couple and Relationship Therapy, 10, 20-33.

Badr, H., Carmack, C. L., Kashy, D. A., Cristofanilli, M., \& Revenson, T. A. (2010). Dyadic coping in metastatic breast cancer. Health Psychology, 29, 169-180.

Bodenmann, G. (2006). Multidimensionaler Stressfragebogen für Paare [Multidimensional Stress Questionnaire]. Unpublished questionnaire. Fribourg, Switzerland: University of Fribourg.

Bodenmann, G. (1997). Dyadic coping - a systemic-transactional view of stress and coping among couples: Theory and empirical findings. European Review of Applied Psychology, 47, 137-140.

Bodenmann, G., \& Shantinath, S. D. (2004). The Couples Coping Enhancement Training (CCET): A new approach to prevention of marital distress based upon stress and coping. Family Relations, 53(5), 477-484.

Bodenmann, G., Ledermann, T., \& Bradbury, T. (2007). Stress, sex, and satisfaction in marriage. Personal Relationships, 14, 551-569. doi:10.1111/j.1475-6811.2007.00171.x.

Bodenmann, G., Plancherel, B., Beach, S. R. H., Widmer, K., Gabriel, B., Meuwly, N., et al. (2008). Effects of coping-oriented couples therapy on depression: A randomized clinical trial. Journal of Consulting and Clinical Psychology, 76, 944-954. doi:10.1037/a0013467.

Bouchard, L. C., \& Shih, J. H. (2013). Gender differences in stress generation: Examination of interpersonal predictors. Journal of Social and Clinical Psychology, 32, 424-445.

Bouras, N., Vanger, P., \& Bridges, P. K. (1986). Marital problems in chronically depressed and physically ill patients and their spouses. Comprehensive Psychiatry, 27, 127-130.

Buck, A. A., \& Neff, L. A. (2012). Stress spillover in early marriage: The role of self-regulatory depletion. Journal of Family Psychology, 26, 698-708. doi:10.1037/a0029260.

Chambless, D. L., Bryan, A. D., Aiken, L. S., Steketee, G., \& Hooley, J. M. (2001). Predicting expressed emotion: A study with families of obsessive-compulsive and agoraphobic outpatients. Journal of Family Psychology, 15, 296-304.

Crawford, J. R., \& Henry, J. D. (2003). The Depression Anxiety Stress Scales (DASS): Normative data and latent structure in a large non-clinical sample. British Journal of Clinical Psychology, 42, 111-131.

Epstein, N. B., \& Baucom, D. H. (2002). Enhanced cognitive-behavioral treatment for couples: A contextual approach. Washington, DC: American Psychological Association.

Federal Statistical Office (2013). Statistical data on Switzerland. Neuchatel: Federal Statistical Office.

Fife Betsy, L., Weaver Michael, T., Cook William, L., \& Stump Timothy, T. (2013). Partner interdependence and coping with life-threatening illness: The impact on dyadic adjustment. Journal of Family Psychology, 27, 702-711. doi:10.1037/a0033871.

Hawkins, D. N., \& Booth, A. (2005). Unhappily ever after: Effects of long-term, low quality marriages on well-being. Social Forces, 84, 445-465.

Hendrick, S. S. (1988). A generic measure of relationship satisfaction. Journal of Marriage and the Family, 50, 93-98.

Hendrick, S. S., Dicke, A., \& Hendrick, C. (1998). The relationship assessment scale. Journal of Social and Personal Relationships, 15, 137-142.

Henry, J. D., \& Crawford, J. R. (2005). The 21-item version of the Depression Anxiety Stress Scales (DASS-21): Normative data and psychometric evaluation in a large non-clinical sample. British Journal of Clinical Psychology, $44,227-239$. 
Herzberg, P. Y. (2012). Coping in relationships: The interplay between individual and dyadic coping and their effects on relationship satisfaction. Anxiety, Stress, \& Coping, 26, 136-153. doi:10.1080/10615806.2012.655726.

Hill, R. (1949). Families under stress: Adjustment to the crises of war separation and reunion. New York: Harper \& Brothers.

Howe, G. W., Levy, M. L., \& Caplan, R. D. (2004). Job loss and depressive symptoms in couples: Common stressors, stress transmission, or relationship disruption. Journal of Family Psychology, 18, 639-650.

Hu, L. T., \& Bentler, P. M. (1999). Cutoff criteria for fit indexes in covariance structure analysis: Conventional criteria versus new alternatives. Structural Equation Modeling, 6, 1-55.

Iafrate, R., Bertoni, A., Margola, D., Cigoli, V., \& Acitelli, L. K. (2012). The link between perceptual congruence and couple relationship satisfaction in dyadic coping. European Psychologist, 17, 73-82.

Kanner, A. D., Coyne, J. C., Schaefer, C., \& Lazarus, R. S. (1981). Comparison of two modes of stress measurements: Daily hassles and uplifts versus major life events. Journal of Behavioral Medicine, 4, 1-39.

Karney, B. R., \& Bradbury, T. N. (1995). The longitudinal course of marital quality and stability: A review of theory, method, and research. Psychological Bulletin, 118, 3-34.

Kenny, D. A., Kashy, D. A., \& Cook, W. L. (2006). Dyadic data analysis. New York: Guilford Press.

Kiecolt-Glasser, J. K., \& Newman, T. L. (2001). Marriage and health: His and hers. Psychological Bulleting, 127, $472-503$.

Koob, G., \& Kreek, M. J. (2007). Stress, dysregulation of drug reward pathways, and the transition to drug dependence. The American Journal of Psychiatry, 164, 1149-1159.

Langer, A., Lawrence, E., \& Barry, R. A. (2008). Using a vulnerability-stress-adaptation framework to predict physical aggression trajectories in newlywed marriage. Journal of Consulting \& Clinical Psychology, 76, 756-768. doi: $10.1037 / \mathrm{a} 0013254$.

Lazarus, R. S., \& Folkman, S. (1984). Stress, appraisal, and coping. New York: Springer.

Lebow, J. L., Chambers, A. L., Christensen, A., \& Johnson, S. M. (2012). Research on the treatment of couple distress. Journal of Marital and Family Therapy, 38, 145-168.

Ledermann, T., Bodenmann, G., Rudaz, M., \& Bradbury, T. N. (2010). Stress, communication, and marital quality. Family Relations, 59, 195-206. doi:10.1111/j.1741-3729.2010.00595.x.

Lemmens, G. M. D., Buysee, A., Heene, E., Eisler, I., \& Demyttenaere, K. (2007). Marital satisfaction, conflict communication, attachment style, and psychological distress in couples with a hospitalized depressed patient. Acta Neuropsychiatrica, 19, 109-117. doi:10.1111/j.1601-5215.2006.00168.x.

Liu, R. T., \& Alloy, L. B. (2010). Stress generation in depression: A systematic review of the empirical literature and recommendations for future study. Clinical Psychology Review, 30, 582-593. doi:10.1016/j.cpr.2010.04.010.

Lovibond, S. H., \& Lovibond, P. F. (1995). Manual for the depression anxiety stress scales (2nd edn). Sydney: Psychology Foundation.

McCubbin, H. I., \& Patterson, J. M. (1983). Family transitions: Adaptation to stress. In H. I. McCubbin \& C. R. Figley (Eds.), Stress and the family: Coping with normative transitions (Vol. 2, pp. 5-25). New York: Brunner/ Mazel.

Mckintosh, E., Gillanders, D., \& Rodgers, S. (2010). Rumination, goal lining, daily hassles, and life events in depression. Clinical Psychology and Psychotherapy, 17, 33-43.

Mohr, G. (1986). Die Erfassung psychischer Befindensbeeinträchtigungen bei Arbeitern [The identification of mental impairment in workers]. Frankfurt a.M.: Peter Lang.

Neff, L. A., \& Karney, B. R. (2005). Gender differences in social support: A question of skill or responsiveness? Journal of Personality and Social Psychology, 88, 79-90.

Neff, L. A., \& Karney, B. R. (2009). Stress and reactivity to daily relationship experiences: How stress hinders adaptive processes in marriage. Journal of Personality and Social Psychology, 97, 435-450.

Nichols, M. P., \& Schwartz, R. C. (2006). Family therapy: Concepts and methods (7th edn). Boston: Allyn \& Bacon.

Ormel, J., Rijsdijk, F. V., Sullivan, M., van Sonderen, E., \& Kempen, G. I. J. M. (2002). Temporal and reciprocal relationship between IADL/ADL disability and depressive symptoms in late life. Journal of Gerontology, 57, 338-347.

Papp, L. M., \& Witt, N. L. (2010). Romantic partners' individual coping strategies and dyadic coping: Implications for relationship functioning. Journal of Family Psychology, 24, 551-559. doi:10.1037/a0020836.

Proulx, C. M., Helms, H. M., \& Buehler, C. (2007). Marital quality and personal well-being. A meta-analysis. Journal of Marriage and Family, 69, 576-593.

Randall, A. K., \& Bodenmann, G. (2009). The role of stress on close relationships and marital satisfaction. Clinical Psychology Review, 29, 105-115. doi:10.1016/j.cpr.2008.10.004.

Revenson, T. A., \& Lepore, S. J. (2012). Stress and coping processes in social context. In T. A. Revenson \& J. E. Singer (Eds.), Handbook of health psychology (2nd ed., pp. 193-217). New York: Psychology Press.

Robles, T. F., \& Kiecolt-Glaser, J. K. (2003). The physiology of marriage: Pathways to health. Physiology \& Behavior, 79, 409-416. doi:10.1016/S0031-9384(03)00160-4. 
Rusli, B. N., Edimansyah, B. A., \& Naing, L. (2008). Working conditions, self-perceived stress, anxiety, depression, and quality of life: A structural-equation modeling approach. BMC Public Health, 8, 1-12. doi:10.1186/14712458-8-48.

Sander, J., \& Böcker, S. (1993). The German version of the Relationship Assessment Scale (RAS): A short scale for measuring satisfaction in a dyadic relationship. Diagnostica, 39, 55-62.

Serido, J., Almeida, D. M., \& Wethington, W. (2004). Chronic stressors and daily hassles: Unique and interactive relationships with psychological distress. Journal of Health and Social Behavior, 45, 17-33. doi:10.1177/ 002214650404500102.

Stefanek, E., Dagmar, S., Hildegunn, F., \& Spiel, C. (2012). Depressive symptoms in native and immigrant adolescents: The role of critical life events and daily hassles. Anxiety, Stress, \& Coping, 25, 201-217.

Story, L. B., \& Bradbury, T. N. (2004). Understanding marriage and stress: Essential questions and challenges. Clinical Psychology Review, 23, 1139-1162.

Swiss Health Observatory (2008). Health in Switzerland. National Health Report 2008. Neuchâtel, Switzerland: Swiss Health Observatory.

Taylor, S. E. (2011). Affiliation and stress. In S. Folkman (Ed.), The Oxford handbook of stress, health, and coping (pp. 86-100). New York: Oxford.

Taylor, S. E., Klein, L. C., Lewis, B. P., Gruenewald, T. L., Gurung, R. A. R., \& Updegraff, J. A. (2000). Behavioral responses to stress in females: Tend-and-befriend, not fight-or-flight. Psychological Review, 107, 411-429.

Totenhagen, C. J., Butler, E. A., \& Ridley, C. A. (2012). Daily stress, closeness, and satisfaction in gay and lesbian couples. Personal Relationships, 19, 219-233.

Umberson, D., Williams, K., Powers, D., Liu, H., \& Needham, B. (2006). You make me sick: Marital quality and health over the life course. Journal of Health and Social Behavior, 47, 1-16.

Untas, A., Quintard, B., Koleck, M., Borteyrou, X., \& Azencot, A. (2009). Impact of the dyadic coping process on the adjustment to a delayed reconstruction after cancer. Annales Medico Psychologiques, 167, 134-141.

Whisman, M. A., \& Uebelacker, L. A. (2009). Prospective associations between marital discord and depressive symptoms in middle-aged and older adults. Psychology and Aging, 24, 184-189.

Williams, L. M. (1995). Association of stressful life events and marital quality. Psychological Reports, 76, 1115-1122.

Yuan, K.-H., \& Bentler, E. M. (2000). Inferences on correlation coefficients in some classes of nonnormal distributions. Journal of Multivariate Analysis, 72, 230-248.

Yuan, K.-H., Lambert, P. L., \& Fouladi, R. T. (2004). Mardia's multivariate kurtosis with missing data. Multivariate Behavioral Research, 39, 413-437.

Zwicker, A., \& DeLongis, A. (2010). Gender, stress, and coping. In J. C. Chrisler \& D. R. McCreary (Eds.), Handbook of gender research in psychology (pp. 495-515). New York, NY: Springer. 